\title{
Plasma AXIN1 expression exhibit negative correlations with inflammatory biomarkers and is associated with gastrointestinal symptoms in endometriosis
}

\author{
KATHARINA DIHM, MALIN EK, BODIL ROTH and BODIL OHLSSON
}

Department of Internal Medicine, Skane University Hospital, Lund University, 20502 Malmo, Sweden

Received October 8, 2019; Accepted February 4, 2020

DOI: $10.3892 /$ br.2020.1282

\begin{abstract}
The cytoplasmic protein AXIN1 is involved in the Wnt signalling pathway and its expression is increased in patients with endometriosis compared with healthy controls. The aim of the present cross-sectional study was to further assess the levels of AXIN1 and other inflammatory biomarkers in patients with endometriosis. Patients with laparoscopy-verified endometriosis were recruited $(n=172)$ and completed a questionnaire regarding socioeconomic factors, lifestyle habits and medical history. Plasma AXIN1 and high-sensitivity C-reactive protein (hs-CRP) levels were analysed by ELISA. The levels of calprotectin were determined in the faeces, and the haemoglobin concentration and number of erythrocytes, leukocytes and platelets were determined in the blood in a subgroup of 64 patients during clinical routine procedures. F-calprotectin expression was detected in 18 women $(28.1 \%)$, who had more severe constipation and more frequently experienced incomplete evacuation when defecating, and 5 women (7.8\%) exhibited elevated levels. P-AXIN1 levels were higher in patients who received hormonal treatment, and correlated inversely with faecal-calprotectin levels $(\mathrm{P}=0.003)$, B-haemoglobin levels $(\mathrm{P}=0.030)$ and the numbers of $\mathrm{B}$-erythrocytes $(\mathrm{P}=0.033)$ and B-platelets $(\mathrm{P}=0.017)$, but were not correlated with hs-CRP levels $(\mathrm{P}=0.818)$. Higher levels of AXIN1 were associated with the duration of the gastrointestinal symptoms and with diarrhoea, constipation, vomiting and nausea and the intestinal symptoms' effect on quality of life, and tended to be associated with the duration of endometriosis. Hs-CRP expression was
\end{abstract}

Correspondence to: Professor Bodil Ohlsson, Department of Internal Medicine, Skane University Hospital, Lund University, Floor 5, 15 Jan Waldenström Street, 20502 Malmo, Sweden E-mail: bodil.ohlsson@med.lu.se

Abbreviations: GI, gastrointestinal; GnRH, gonadotropin-releasing hormone; hs-CRP, high-sensitivity c-reactive protein; IBS, irritable bowel syndrome

Key words: AXIN1, calprotectin, endometriosis, gastrointestinal symptoms, inflammatory biomarkers not associated with the clinical characteristics or symptoms of endometriosis, but higher levels were associated with obesity $(\mathrm{P}=0.002)$ and hormonal treatment $(\mathrm{P}=0.011)$. In conclusion, P-AXIN1 expression was negatively correlated with certain inflammatory biomarkers and was positively associated with gastrointestinal symptoms. P-AXIN1 levels were increased in patients who received hormonal treatment, highlighting the importance of obtaining native samples for future studies regarding its role in the development and presentation of endometriosis. However, hs-CRP and other studied biomarkers seemed to be of no value for the assessment and diagnosis of endometriosis.

\section{Introduction}

Endometriosis is defined as the presence of oestrogen-dependent endometrial tissue outside the uterus and affects 5-10\% of women of reproductive age (1-3). Although endometriosis is a benign, chronic inflammatory disease, its pathophysiology remains unclear (1-4). Diagnosis of endometriosis is performed by laparoscopy and confirmed by histopathological examination of sample biopsies (5). This procedure in combination with the presence of non-specific symptoms, such as dysmenorrhea, pelvic pain, dyspareunia, gastrointestinal (GI) symptoms and infertility, lead to diagnostic delays of 6-7 years $(3,4)$. Specifically, GI symptoms can easily be misinterpreted for irritable bowel syndrome (IBS), a common GI disorder affecting $\sim 10 \%$ of adults (4). At present, there are no independent validated biomarkers for diagnosis of endometriosis or to explain the GI symptoms, despite the promising ongoing research in this field $(2,6)$.

A recent study described increased levels of the cytoplasmic protein AXIN1 in patients with laparoscopically confirmed endometriosis compared with those of the control subjects (7). AXIN1 downregulates activity of the Wnt signalling pathway, which serves a role in a number of biological processes, including cellular proliferation, tissue homeostasis, development of the immune system and other systemic effects (8-10). Further investigation of AXIN1, and on its associations with several subtypes of endometriosis may allow for a deeper understanding of this disease. In addition, investigation of the potential correlation of AXIN1 expression with the expression of other readily measurable inflammatory markers, such as high-sensitivity c-reactive protein (hs-CRP) 
and faecal-calprotectin (F-calprotectin), may potentially offer additional diagnostic information, as these proteins have been demonstrated to be useful biomarkers in detecting inflammation $(11,12)$. These factors may be altered in chronic inflammation and are performed as routine analyses in daily clinical practice (6). Although hs-CRP is irrelevant for the diagnosis of endometriosis (13), it has been used as a marker with high sensitivity to diagnose diseases with GI symptoms, such as IBS (11). Therefore, it could potentially be used to explain GI symptoms in patients with endometriosis. The plasma levels of calprotectin have been hypothesized to serve an important role in a number of gynaecological conditions, including cervical inflammation $(14,15)$. F-calprotectin is the biomarker with the highest sensitivity for local inflammation in the GI tract $(16,17)$. To the best of our knowledge, calprotectin has not been previously measured in faecal samples of patients with endometriosis, although intestinal involvement is often noted in this disease $(3,4)$.

The present study measured the expression levels of inflammatory biomarkers, and examined whether they were associated with clinical signs of endometriosis, such as duration, localisation of disease and GI symptoms. To address this hypothesis, the correlations between plasma levels of AXIN1 and hs-CRP were examined in association with F-calprotectin and haemoglobin levels, as well as the number of erythrocytes, leukocytes and platelets in the blood of 64 patients with endometriosis. Furthermore, the correlations and the differences in the levels of these biomarkers were calculated in association with clinical signs and GI symptoms. In a larger cohort of 172 patients, the associations were examined between AXIN1 and hs-CRP plasma levels and disease characteristics, clinical symptoms and medical treatment. The aim of the present study was to investigate the potential relevance of AXIN1 expression and of inflammatory biomarkers, including hs-CRP and F-calprotectin, in patients with endometriosis. The study further aimed to evaluate the correlations between these inflammatory biomarkers and the clinical signs and GI symptoms of the patients with endometriosis.

\section{Materials and methods}

Ethics approval and consent to participate. The present study was performed according to the Declaration of Helsinki (18). Ethical approval was obtained from the Ethics Review Board of Lund University [approval nos. 2012/564 (09/10/2012) and 2016/56 (03/05/2016)]. All participants provided written informed consent prior to participation.

Study participants. Patients with laparoscopy-verified endometriosis were recruited to the present cross-sectional study at the Department of Gynaecology, Skane University Hospital, Malmo, Sweden. The first cohort was recruited between March 2013 and July 2014 and included 100 women, and the second recruitment phase was between September 2016 and March 2017, with 72 women. Therefore, in total 172 women, median age 38 year (age range 19-50 years), were recruited for the present study. The details of patient recruitment, and the inclusion and exclusion criteria are described in detail elsewhere, along with the basal characteristics of the cohort $(7,19)$.
Study design. All participants were interviewed and completed a questionnaire regarding their sociodemographic factors, lifestyle habits and medical history, as well as the validated visual analogue scale for irritable bowel syndrome (VAS-IBS) (20). The blood samples were collected and centrifuged at 1,000 x g for $10 \mathrm{~min}$, at $4^{\circ} \mathrm{C}$. Whole blood, plasma and serum were frozen at $-20^{\circ} \mathrm{C}$ and $/$ or at $-80^{\circ} \mathrm{C}$, and analysis of the plasma levels of AXIN1 and hs-CRP was performed.

In the second cohort of 72 patients, faecal samples were collected from 64 patients, frozen at $-80^{\circ} \mathrm{C}$, and analysed for F-calprotectin according to the clinical routines at the Department of Clinical Chemistry (21). Therefore, the inflammatory markers investigated in blood, such as haemoglobin, erythrocytes, leukocytes and platelets, were only measured for those 64 patients, according to the clinical routines at the Department of clinical Chemistry (21).

Gastrointestinal symptoms. The VAS-IBS questionnaire assesses the severity of several GI symptoms, such as abdominal pain, diarrhoea, constipation, bloating and flatulence, vomiting and nausea, psychological well-being and the effect of intestinal symptoms on the quality of the patients' life over the last 2 weeks. The severity of these symptoms is measured on a continuous scale from 0-100 mm, where 100 represents severe symptoms and 0 no symptoms. The scales were inverted from the original version, prior to the analysis. In addition, two dichotomous questions probed the experience of defecation urgency and the sensation of incomplete evacuation. The replies were determined by 'yes' or 'no' (20). The reference values from 52 healthy women, recruited from hospital staff (median age 44 years, range 22-77 years), who had not undergone prior abdominal surgery, were used as controls as previously published (22).

Biological sample analysis. Haemoglobin, erythrocytes, leukocytes and platelets in blood (B), and hs-CRP levels in plasma $(\mathrm{P})$ were analysed according to clinical routine procedures at the Department of Clinical Chemistry. The reference values for healthy individuals were obtained from the same department using the same methods as described above. F-calprotectin levels were analysed by ELISA [CalproLab ${ }^{\mathrm{TM}}$ ELISA TEST (ALP/HRP); Calpro AS] at the Department of Clinical Chemistry. The lowest detection levels were $25 \mathrm{mg} / \mathrm{kg}$. Values $<50 \mathrm{mg} / \mathrm{kg}$ were considered normal, $50-100 \mathrm{mg} / \mathrm{kg}$ was considered a grey zone and those $>100 \mathrm{mg} / \mathrm{kg}$ were considered pathological (21). Values in the grey zone may occur also be observed in the healthy subjects, and the clinical significance of values in this range is unclear. Plasma AXIN1 levels were analysed using sandwich ELISA (cat. no. MBS762601; MyBioSource, Inc.; lot no. H2497C119) according to the manufacturer's protocol (7).

Data categorization. Body mass index (BMI) was divided into normal-weight $\left(<25 \mathrm{~kg} / \mathrm{m}^{2}\right)$, overweight $\left(25-29.9 \mathrm{~kg} / \mathrm{m}^{2}\right)$ or obese $\left(\geq 30 \mathrm{~kg} / \mathrm{m}^{2}\right)$ according to the WHO classification (23). Smoking habits were divided into non-smokers (at examination) and smokers. Physical activity was divided into $<1 \mathrm{~h}$ or $\geq \mathrm{h}$ per week. Alcohol consumption was divided into drinking $>1$ or at least 1 standard glass of alcohol per week. The localisation of endometriosis was divided into isolated or 
Table I. Clinicopathological characteristics of the 64 patients in the second cohort with available faecal samples.

Clinicopathological characteristics

Age, year (IQR)

BMI, $\mathrm{kg} / \mathrm{m}^{2}(\mathrm{IQR})$

Smoking, n (\%)

Alcohol consumption $\geq 1$ standard glass/week, $\mathrm{n}(\%)$

Physical activity $\geq 1 \mathrm{~h} /$ week, $\mathrm{n}(\%)$

Duration of endometriosis diagnosis, years (IQR)

Duration of GI symptoms, year (IQR)

Isolated ovarian endometriosis, $\mathrm{n}(\%)$

Bowel endometriosis affecting the GI tract alone or along with other locations, $\mathrm{n}(\%)$

Current hormonal treatment, n (\%)

Current opioid treatment, n (\%)

Abdominal pain, mm

Experimental values

Reference values

Diarrhoea (mm)

Experimental values

Reference values

Constipation (mm)

Experimental values

Reference values

Bloating and flatulence ( $\mathrm{mm})$

Experimental values

Reference values

Vomiting and nausea (mm)

Experimental values

Reference values

Psychological well-being (mm)

Experimental values

Reference values

Intestinal symptoms' affected quality of life (mm)

Experimental values

Reference values

Defecation urgency, n (\%)

Incomplete evacuation when defecating, n (\%)
Values

$38.00(32.25-42.75)$

$24.78(21.92-28.00)$

10 (15.6)

24 (37.5)

$26(40.6)$

$12.00(5.00-19.25)$

$16.50(7.00-21.00)$

$26(40.6)$

$18(28.1)$

$40(62.5)$

$11(17.2)$

43 (13-72)

$5(1-15)$

$17(2-60)$

$3(0-10)$

$26(2-56)$

$9(1-22)$

61 (19-76)

14 (1-29)

$15(2-50)$

$2(0-3)$

$32(12-62)$

4 (0-16)

51 (16-78)

2 (0-18)

22 (34.4)

37 (57.8)

IQR, inter-quartile range; BMI, body mass index; GI, gastrointestinal.

non-isolated ovarian lesions, independent of the localisation of the spread lesions, and to subjects with or without bowel involvement. Medical treatment was divided into current use or not currently using (at examination), independent of the history of use. Age, duration of disease and GI symptoms as well as VAS-IBS scales were divided into quartiles for the calculations with logistic regression.

Statistical analysis. In the present study, two hypotheses were examined: i) Different inflammatory biomarkers were correlated with each other; and ii) the levels of inflammatory biomarkers were affected by disease characteristics, clinical signs, GI symptoms and medical treatment. The expression levels of hs-CRP and F-calprotectin that were below the limit of detection were set to the lowest detectable level $(0.6 \mathrm{mg} / \mathrm{l}$ and $25 \mathrm{mg} / \mathrm{kg}$, respectively). All variables were found to be non-normally distributed and analysis was performed using a Fisher's exact test, Spearman's correlation test or a Mann Whitney U test. To further assess the association between the expression levels of AXIN1 and hs-CRP, binary logistic regression was performed with the biomarkers as the dependent variables and stratified according to the median value into lower or higher levels, and sociodemographic factors, medication and GI symptoms were the independent variables. The lowest category was set as the reference. P-values for trend and for log-transformed, continuous variables were calculated. 
Table II. Inflammatory biomarkers and their correlations with AXIN1 and hs-CRP levels in plasma.

\begin{tabular}{|c|c|c|c|c|c|c|c|}
\hline \multirow[b]{2}{*}{ Biomarkers } & \multirow[b]{2}{*}{ Normal range } & \multirow[b]{2}{*}{$\begin{array}{l}\text { Pathological } \\
\text { values, n (\%) }\end{array}$} & \multirow[b]{2}{*}{ Median (IQR) } & \multicolumn{2}{|c|}{ AXIN1 } & \multicolumn{2}{|c|}{ hs-CRP } \\
\hline & & & & $\begin{array}{l}\text { Correlation } \\
\text { coefficient }\end{array}$ & P-value & $\begin{array}{c}\text { Correlation } \\
\text { coefficient }\end{array}$ & P-value \\
\hline P-AXIN1 & N/A & - & $\begin{array}{c}390.00 \\
(357.50-420.00)\end{array}$ & 1.00 & - & -0.053 & 0.682 \\
\hline F-calprotectin & $<50 \mathrm{mg} / \mathrm{kg}$ & $11(17.2)$ & $\begin{array}{c}25.00 \\
(25.00-29.50)\end{array}$ & -0.368 & $0.003^{b}$ & 0.280 & $0.028^{\mathrm{a}}$ \\
\hline B-haemoglobin & $117-153 \mathrm{~g} / \mathrm{l}$ & $12(18.8)$ & $\begin{array}{c}124.00 \\
(118.00-127.25)\end{array}$ & -0.276 & $0.030^{\mathrm{a}}$ & -0.041 & 0.752 \\
\hline B-erythrocytes & $3.9-5.2 \times 10^{12} / 1$ & $7(11.0)$ & $\begin{array}{c}4.28 \\
(4.08-4.50)\end{array}$ & -0.271 & $0.033^{\mathrm{a}}$ & 0.019 & 0.885 \\
\hline B-leukocytes & $3.5-8.8 \times 10^{9} / 1$ & $18(28.2)$ & $\begin{array}{c}7.75 \\
(6.50-9.12)\end{array}$ & -0.177 & 0.168 & 0.288 & $0.023^{\mathrm{a}}$ \\
\hline B-platelets & $165-387 \times 10^{9} / 1$ & $3(4.7)$ & $\begin{array}{c}265.50 \\
(218.75-324.75)\end{array}$ & -0.302 & $0.017^{\mathrm{a}}$ & 0.208 & 0.104 \\
\hline P-hs-CRP & $<3.0 \mathrm{mg} / \mathrm{l}$ & $16(25.0)$ & $\begin{array}{c}1.10 \\
(0.60-3.22)\end{array}$ & -0.050 & 0.758 & 1.00 & - \\
\hline
\end{tabular}

${ }^{\text {a }} \mathrm{P}<0.05,{ }^{\mathrm{b}} \mathrm{P}<0.01$. B, blood; $\mathrm{P}$, plasma; F, faecal; hs-CRP, high sensitivity-C-reactive protein; IQR, interquartile range.

The values are presented as the number (percentage), median (interquartile range), or odds ratio (OR) and $95 \%$ confidence interval (CI). The data were analysed using SPSS version 25.0 (IBM, Corp.). $\mathrm{P}<0.05$ was considered to indicate a statistically significant difference.

\section{Results}

Basal characteristics. The majority of the 64 patients from the second cohort (55 patients, $85.9 \%$ ) had suffered from GI complaints during the 2 weeks prior to their inclusion in the study. A limited percentage of the patients (10 patients, 15.6\%) were smokers and 38 patients $(59.4 \%)$ had a low physical activity. A total of 40 patients $(62.5 \%)$, were treated with hormonal therapy, in some cases with more than one drug. A total of 20 women $(31.3 \%)$ were treated with oestrogen or combined oral contraception, whereas 19 women $(29.7 \%)$ were treated with progestin and 7 women $(10.9 \%)$ were treated with gonadotropin-releasing hormone $(\mathrm{GnRH})$ analogues. In addition, 11 women (17.2\%) were treated with opioids (Table I).

Inflammatory biomarkers. The majority of the women in the present study exhibited biomarker levels within the normal reference range (Table II). P-AXIN1 expression levels were negatively correlated with F-calprotectin levels (Table II) and haemoglobin levels (Fig. 1), as well as the number of erythrocytes (Fig. 2) and platelets (Fig. 3). P-hs-CRP levels were positively correlated with F-calprotectin levels and the number of B-leukocytes (Table II).

B-haemoglobin levels were significantly correlated with age (Fig. 4), whereas patients with physical activity $\geq 1 \mathrm{~h} /$ week had a lower number of B-erythrocytes compared with women with less physical activity [4.20 (4.04-4.32) $\mathrm{x} 10^{12} / 1$ vs. $\left.4.38(4.19-4.64) \times 10^{12} / 1, \mathrm{P}=0.040\right]$, without affecting haemoglobin concentration (data not shown). The expression levels of B-haemoglobin and the numbers of B-erythrocytes, B-leukocytes and B-platelets were not associated with BMI, smoking, alcohol consumption, duration of endometriosis (based on the date when the diagnosis was performed), duration or degree of GI symptoms, treatment provided or localisation of endometriosis (data not shown).

Of the 64 women examined from the second cohort, 18 women $(28.1 \%)$ presented with F-calprotectin levels $>25 \mathrm{mg} / \mathrm{kg}, 6$ women (9.4\%) exhibited grey zone levels, and 5 women $(7.8 \%)$ had high F-calprotectin levels. The patients with F-calprotectin values $\leq 25 \mathrm{mg} / \mathrm{kg}(\mathrm{n}=46,71.9 \%)$ exhibited higher AXIN1 levels [400 (370-430) pg/ml vs. 350 (340-380) pg/ml; $\mathrm{P}=0.002]$ and lower hs-CRP values $[1$ (0.6-1.8) $\mathrm{mg} / 1 \mathrm{vs} .2 .7$ (0.69-6.35) $\mathrm{mg} / \mathrm{l} ; \mathrm{P}=0.029]$, compared with the patients with measurable F-calprotectin levels. Women with F-calprotectin levels $>25 \mathrm{mg} / \mathrm{kg}$ experienced higher degrees of constipation [50.50 (11.00-71.50) mm vs. 16.50 (2.00-45.50) $\mathrm{mm} ; \mathrm{P}=0.048]$. These subjects experienced more frequent incomplete evacuation when defecating $[n=14(87.5 \%)$ vs. $n=23(50.0 \%) ; P=0.009]$, compared to women with F-calprotectin levels $\leq 25 \mathrm{mg} / \mathrm{kg}$. The localisation and duration of endometriosis were not associated with the levels of F-calprotectin (data not shown).

Correlations between AXIN1 and hs-CRP levels in the plasma of the patients. To further assess the correlations between AXIN1 and hs-CRP levels in the plasma, and their association with the clinical signs and the GI symptoms of endometriosis, the total cohort of 172 patients with a median age of 38 years (age range 19-50 years) and a median BMI of $24.34(21.80-27.10) \mathrm{kg} / \mathrm{m}^{2}$ was used (19). The median levels of AXIN1 were 300 (170-380) pg/ml, and for hs-CRP levels $1.10(0.60-3.25) \mathrm{mg} / \mathrm{l}$. A total of 80 patients (46.5\%) were treated with hormonal treatment. A total of 42 women $(24.4 \%)$ 


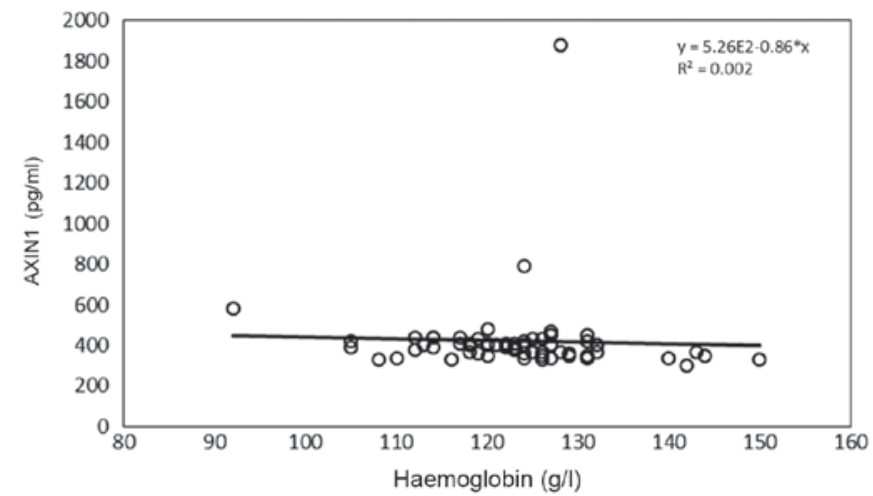

Figure 1. Scatter plot showing the inverse correlation between blood haemoglobin and plasma AXIN1 levels. $r=-0.368$. $\mathrm{P}=0.03$.

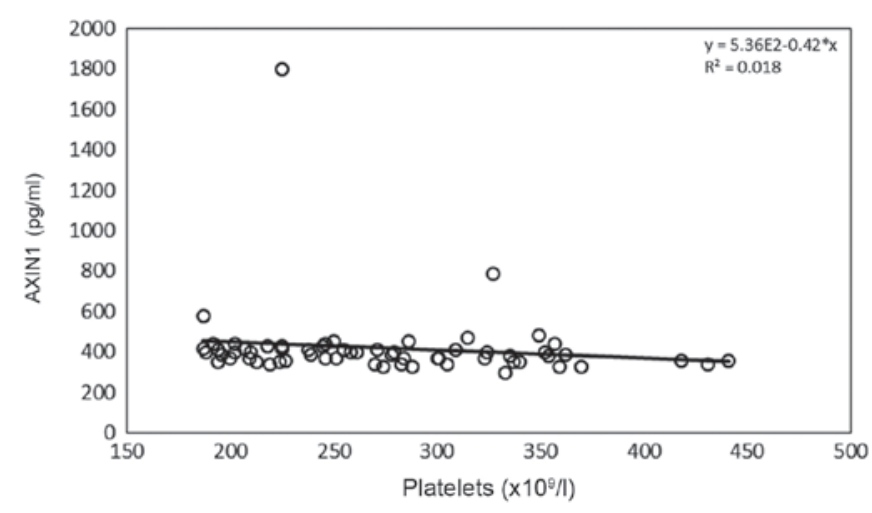

Figure 3. Scatter plot showing the inverse correlation between blood platelets and plasma AXIN1 levels. $\mathrm{r}=-0.302$. $\mathrm{P}=0.017$.

were treated with oestrogen or combined oral contraception, whereas 30 women $(17.4 \%)$ were treated with progestin and 15 women $(8.7 \%)$ were treated with GnRH analogues. A total of 30 women $(17.4 \%)$ were treated with opioids (Table SI). A total of 92 patients $(53.5 \%)$ could distinguish between symptoms from the GI tract and their endometriosis symptoms; whereas for 49 patients $(28.5 \%)$, the origin of the GI symptoms could not be determined.

There was no correlation between AXIN1 and hs-CRP levels ( $\mathrm{r}=-0.018 ; \mathrm{P}=0.818)$. BMI was correlated with hs-CRP levels $(\mathrm{r}=0.288 ; \mathrm{P}<0.001)$. AXIN1 levels were not correlated with BMI $(\mathrm{P}=0.700)$, but were correlated with the duration of endometriosis $(\mathrm{r}=0.172 ; \mathrm{P}=0.047)$ and the duration of GI symptoms $(\mathrm{r}=0.244 ; \mathrm{P}=0.009)$. Furthermore, significant correlations were identified between AXIN1 levels and the degree of vomiting and nausea $(\mathrm{r}=0.176 ; \mathrm{P}=0.024)$ as well as with the intestinal symptoms' effect on the quality of life $(\mathrm{r}=0.222 ; \mathrm{P}=0.004)$. Hs-CRP levels were not correlated with specific GI symptoms (data not shown). Women that were treated with hormonal therapy exhibited higher levels of AXIN1 and hs-CRP compared with those without treatment $(\mathrm{P}=0.036$ and $\mathrm{P}<0.001$, respectively). Treatment with oestrogen, combined oral contraception $(\mathrm{P}=0.048$ and $\mathrm{P}<0.001$, respectively) and progestin $(\mathrm{P}=0.010$ and $\mathrm{P}=0.036$, respectively) also affected the levels of the aforementioned markers (Table III). Neither AXIN1, nor hs-CRP levels, were affected by treatment with $\mathrm{GnRH}$ analogues $(\mathrm{P}=1.000$

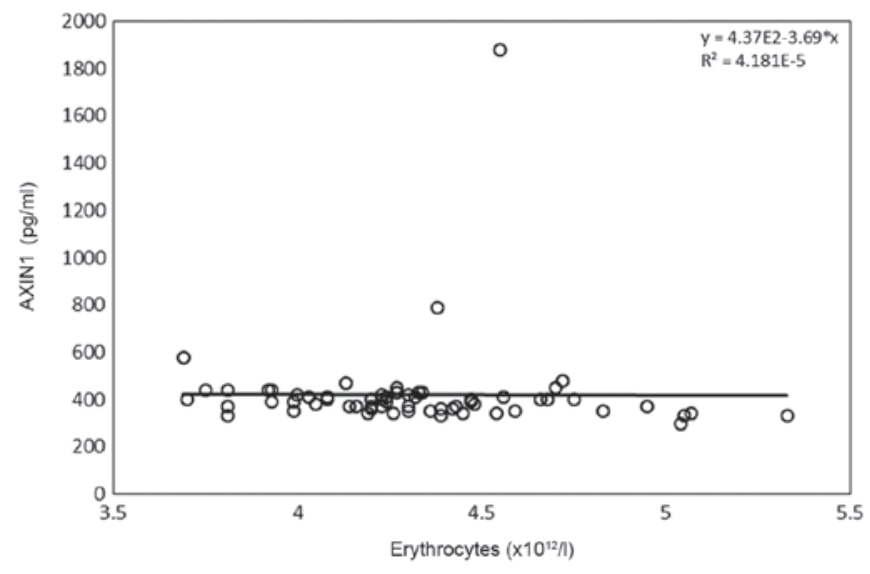

Figure 2. Scatter plot showing the inverse correlation between blood erythrocytes and plasma AXIN1 levels. $\mathrm{r}=-0.271, \mathrm{P}=0.033$.

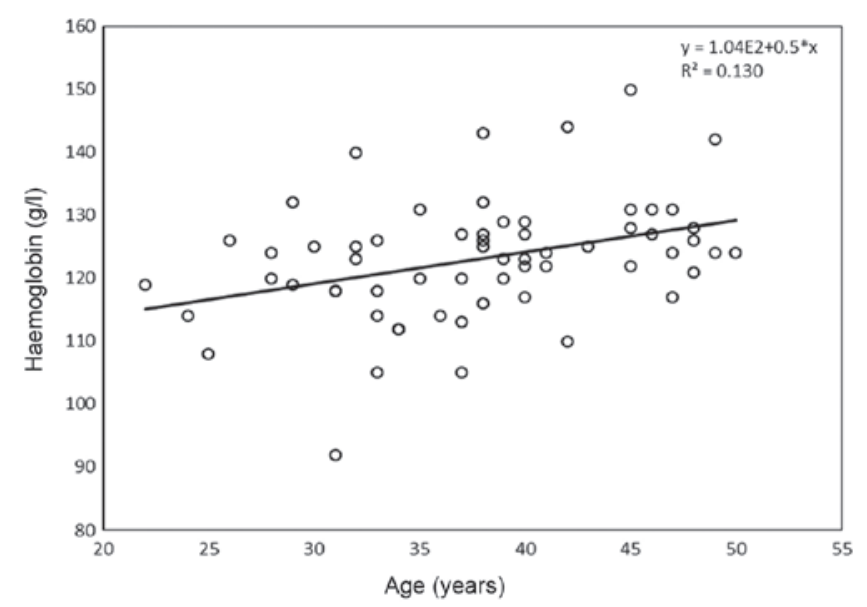

Figure 4. Scatter plot showing the correlation between blood haemoglobin and age. $\mathrm{r}=0.370, \mathrm{P}=0.003$.

and $\mathrm{P}=0.657$, respectively) or opioid treatment $(\mathrm{P}=0.375$ and $\mathrm{P}=0.423$, respectively).

In the women whom did not undergo hormonal treatment $(n=92)$, there was a significant correlation between their AXIN1 levels and the duration of GI symptoms $(r=0.270$, $\mathrm{P}=0.044)$ or the effect of intestinal symptoms on quality of life $(\mathrm{r}=0.301 ; \mathrm{P}=0.005)$, whereas, there was no significant correlation between AXIN1 levels, the duration of endometriosis symptoms and the degree of vomiting and nausea $(\mathrm{P}=0.128$ and $\mathrm{P}=0.337$, respectively). Hs-CRP levels were correlated with BMI $(r=0.229, \mathrm{P}=0.036)$, following exclusion of the patients who underwent hormonal treatment.

Following logistic regression analysis, no associations were noted between AXIN1 levels and sociodemographic factors or other characteristics. However, there was a clear tendency towards an association with hormonal treatment $(\mathrm{P}=0.061$; Table IV). The duration of GI symptoms and the degree of diarrhoea, constipation, vomiting and nausea, and the effect of intestinal symptoms on quality of life were all associated with higher levels of AXIN1 (Table V). Hs-CRP levels were associated with higher BMI values and with hormonal treatment. These conclusions remained following adjustment for both variables [OR, 11.704 (CI, 2.486-55.108), 
Table III. AXIN1 and hs-CRP levels in patients treated with different hormonal treatments.

\begin{tabular}{|c|c|c|c|c|}
\hline \multirow[b]{2}{*}{ Treatment } & \multicolumn{2}{|c|}{ AXIN1, pg/ml } & \multicolumn{2}{|c|}{ hs-CRP, mg/l } \\
\hline & Median (IQR) & P-value & Median (IQR) & P-value \\
\hline Current hormonal treatment & & 0.036 & & $<0.001^{\mathrm{b}}$ \\
\hline Yes, $n=80$ & $340.00(187.50-400.00)$ & & $1.65(0.74-4.68)$ & \\
\hline No, $n=92$ & $270.00(160.00-370.00)$ & & $0.77(0.60-2.20)$ & \\
\hline Current oestrogen or combined oral contraception & & 0.048 & & $<0.001^{\mathrm{b}}$ \\
\hline Yes, $n=42$ & $360.00(210.00-400.00)$ & & $2.70(0.99-4.80)$ & \\
\hline No, $n=92$ & $270.00(160.00-370.00)$ & & $0.77(0.60-2.20)$ & \\
\hline Current progestin treatment & & 0.010 & & $0.036^{\mathrm{a}}$ \\
\hline Yes, $\mathrm{n}=30$ & $350.00(260.00-420.00)$ & & $1.50(0.74-4.10)$ & \\
\hline No, $n=92$ & $270.00(160.00-370.00)$ & & $0.77(0.60-2.20)$ & \\
\hline
\end{tabular}

${ }^{\mathrm{a}} \mathrm{P}<0.05,{ }^{\mathrm{b}} \mathrm{P}<0.001$. Hs-CRP, high sensitivity-C-reactive protein; IQR, interquartile range.

$\mathrm{P}=0.002$ for obese individuals compared with normal-weight individuals and OR, 2.361 (CI, 1.215-4.588), $\mathrm{P}=0.011$ for hormonal treatment compared with no hormonal treatment, respectively). The localisation of endometriosis did not affect plasma levels of AXIN1 (Table IV) or hs-CRP (data not shown).

\section{Discussion}

The primary findings of the present study were that there was a negative correlation between P-AXIN1 levels and the levels of F-calprotectin, B-haemoglobin as well as the number of B-erythrocytes and B-platelets. Furthermore, there was a positive correlation between P-AXIN1 levels and the duration of endometriosis, duration of GI symptoms as well as the degree of certain GI symptoms. In a logistic regression model, significant associations were identified between higher AXIN1 levels and the duration of GI symptoms, the degree of diarrhoea, constipation, vomiting and nausea and the intestinal symptoms' effect on quality of life. Furthermore, P-AXIN1 levels were increased in patients with hormonal treatment. Higher hs-CRP levels were associated with obesity and hormonal treatment.

AXIN1 acts as a repressor of the Wnt signalling pathway (8). Additionally, AXIN1 expression is increased in women with endometriosis compared with the expression in control subjects (7). The Wnt signalling pathway is responsible for a number of biological processes including growth and proliferation of cells in various organs $(9,10)$. Previous studies suggested that this pathway enabled tissue regeneration, which could improve wound repair $(9,24)$. Dysregulation of the Wnt signalling pathway is attributed to a number of diseases, such as ovarian cancer, intestinal inflammation, bacterial infection and autoimmune disorders $(9,10,24-29)$. The mechanisms of action of the Wnt signalling pathway have been previously described $(8,9,24,26,28,30-32)$. AXIN1 acts as a scaffolding protein, which interacts with other proteins, such as GSK3,APC, CK $1 \alpha$ and $\beta$-catenin (9). By building a 'destruction complex', AXIN1 negatively regulates the Wnt signalling pathway via phosphorylation of $\beta$-catenin $(9,24)$. It has been suggested that
AXIN1 is the rate limiting protein of the destruction complex, which suggests that the increase in AXIN1 expression represents the increased destruction of $\beta$-catenin and the inhibition of the Wnt signalling pathway $(9,26)$. However, the quantitative ratios of other proteins involved in the Wnt signalling pathway or in $\beta$-catenin degradation have to be established to confirm this hypothesis (9). The findings of the present study showed there was a negative correlation between AXIN1 levels and certain inflammatory markers, which reflects the complex and intimate regulation between several inflammatory pathways and the Wnt signalling pathway (9,24,30-32).

It has been suggested that aberrant activation of the Wnt signalling pathway may promote the development of endometriosis through increased cell migration and invasion $(33,34)$. It remains to be determined whether the increased levels of AXIN1 and the downregulation of the Wnt signalling pathway serve as an initiating step in the development and establishment of endometriosis, or whether the elevated AXIN1 levels are a secondary compensatory mechanism in response to increased $\beta$-catenin levels. It is also unclear whether AXIN1 is a proor an anti-inflammatory factor. An anti-inflammatory effect of AXIN1 would explain the inverse correlation with other inflammatory biomarkers. Further research is required in order to exclude the effects of hormonal treatment on AXIN1 levels, and to establish the causal link between increased AXIN1 levels and decreased levels of other inflammatory biomarkers. Higher AXIN1 and hs-CRP levels were observed in the treated patients of the present cross-sectional study. These levels may hypothetically indicate that hormonal treatment is given to the patients with the highest levels of inflammation. Furthermore, the therapeutic effect of hormonal therapy may be mediated by increased AXIN1 levels. Blood samples should be collected before commencing treatment for suspected endometriosis, and the patients should be re-examined regularly.

AXIN1 levels were positively associated with several GI symptoms. Approximately half of the patients could distinguish whether the symptoms originated from the GI tract or whether they were of gynaecological origin. Nevertheless, it is unclear whether the patients who could distinguish their symptoms had only referred to symptoms from the GI tract in their 
Table IV. Associations between sociodemographic factors and medical history with AXIN1 levels.

\begin{tabular}{|c|c|c|c|c|c|}
\hline Characteristics & $\begin{array}{c}\text { AXIN1 } \\
<300 \mathrm{pg} / \mathrm{ml}, \\
\mathrm{n}=82\end{array}$ & $\begin{array}{c}\text { AXIN1 } \\
\geq 300 \mathrm{pg} / \mathrm{ml}, \\
\mathrm{n}=86\end{array}$ & Odds ratio & $\begin{array}{l}\text { 95\% Confidence } \\
\text { intervals }\end{array}$ & P-value \\
\hline \multicolumn{6}{|l|}{ Age, years, n (\%) } \\
\hline$<33$ & $21(25.6)$ & $22(25.6)$ & 1 & & \\
\hline $33-37$ & $24(29.3)$ & $20(23.3)$ & 0.795 & $0.343-1.847$ & 0.594 \\
\hline $38-42$ & $18(22.0)$ & $22(25.6)$ & 1.167 & $0.492-2.767$ & 0.726 \\
\hline$\geq 43$ & $19(23.2)$ & $22(25.6)$ & 1.105 & $0.469-2.604$ & 0.819 \\
\hline \multicolumn{6}{|l|}{$\mathrm{BMI}, \mathrm{kg} / \mathrm{m}^{2}, \mathrm{n}(\%)$} \\
\hline$<25$ & $50(61.0)$ & $47(54.7)$ & 1 & & \\
\hline $25-29.9$ & $25(30.5)$ & $26(30.2)$ & 1.106 & $0.562-2.180$ & 0.770 \\
\hline$\geq 30$ & $6(7.3)$ & $11(12.8)$ & 1.950 & $0.668-5.694$ & 0.222 \\
\hline Missing & $1(1.2)$ & $2(2.3)$ & - & - & - \\
\hline \multicolumn{6}{|l|}{ Smoking, n (\%) } \\
\hline No smoking & $68(82.9)$ & $74(86.0)$ & 1 & & \\
\hline Smoking & $14(17.1)$ & $11(12.8)$ & 0.722 & $0.307-1.699$ & 0.456 \\
\hline Missing & & $1(1.2)$ & - & - & - \\
\hline \multicolumn{6}{|c|}{ Alcohol consumption, n (\%) } \\
\hline$<1$ glass/week & $53(64.6)$ & $51(59.3)$ & 1 & & \\
\hline$\geq 1$ glass/week & $29(35.4)$ & $34(39.5)$ & 1.218 & $0.651-2.281$ & 0.537 \\
\hline Missing & & $1(1.2)$ & - & - & - \\
\hline \multicolumn{6}{|l|}{ Physical activity, n (\%) } \\
\hline$<1 \mathrm{~h} /$ week & $37(45.1)$ & $48(55.8)$ & 1 & & \\
\hline$\geq 1 \mathrm{~h} /$ week & $45(54.9)$ & $37(43.0)$ & 0.634 & $0.344-1.167$ & 0.143 \\
\hline Missing & & $1(1.2)$ & - & - & - \\
\hline \multicolumn{6}{|c|}{ Duration of endometriosis, year, $\mathrm{n}(\%)$} \\
\hline$<5$ & $21(25.6)$ & $10(11.6)$ & 1 & & \\
\hline $5-10$ & $17(20.7)$ & $18(20.9)$ & 2.224 & $0.815-6.064$ & 0.118 \\
\hline $11-17$ & $17(20.7)$ & $10(20.9)$ & 2.224 & $0.815-6.064$ & 0.118 \\
\hline$\geq 18$ & $15(18.3)$ & $17(19.8)$ & 2.380 & $0.855-6.628$ & 0.097 \\
\hline Missing & $12(14.6)$ & $23(26.7)$ & - & - & - \\
\hline \multicolumn{6}{|c|}{ Localisation of endometriosis, $\mathrm{n}(\%)$} \\
\hline Ovarian & $31(37.8)$ & $34(39.5)$ & 1 & & \\
\hline Outside ovarian & $47(57.3)$ & $50(58.1)$ & 0.970 & $0.517-1.819$ & 0.924 \\
\hline Missing & $4(4.9)$ & $2(2.3)$ & - & - & - \\
\hline \multicolumn{6}{|l|}{ Treatment, n (\%) } \\
\hline No hormonal treatment & $50(61.0)$ & $40(46.5)$ & 1 & & \\
\hline Hormonal treatment & $32(39.0)$ & $46(53.5)$ & 1.797 & $0.973-3.319$ & 0.061 \\
\hline
\end{tabular}

answers, or if the symptoms represented complaints from both sites. Therefore, it is unclear what the symptoms mean, and the only evidence presented was that the patient suffered from GI symptoms, as described previously $(3,4)$. However, independent of whether the patient can distinguish their symptoms from different organs, the GI symptoms may have the same or similar underlying pathophysiology. Low-grade inflammation and visceral hypersensitivity are considered important factors in the aetiology of the GI symptoms in both IBS and endometriosis $(4,35)$. The association between GI symptoms and AXIN1 levels seemed to be unique for endometriosis, since AXIN1 levels in patients with MC (7) and IBS (unpublished data) did not exhibit an association with GI symptoms. However, the associations may be influenced by psychological factors that in turn affect both nausea and the influence of symptoms on the quality of life (36). The lower number of patients may explain the fact that some correlations disappeared following exclusion of patients with hormonal treatment. Therefore, the reduced correlation and loss of significance do not necessarily indicate the absence of correlations.

Hs-CRP levels were not correlated with AXIN1 levels, or associated with disease duration or the degree of GI symptoms. These findings support previous studies stating that hs-CRP levels are irrelevant in the diagnosis of endometriosis (13). The 
Table V. Associations between GI symptoms and lower or higher AXIN1 levels.

\begin{tabular}{|c|c|c|c|c|c|}
\hline Characteristics & $\begin{array}{c}\text { AXIN1 } \\
<300 \mathrm{pg} / \mathrm{ml}, \\
\mathrm{n}=82\end{array}$ & $\begin{array}{c}\text { AXIN1 } \\
\geq 300 \mathrm{pg} / \mathrm{ml}, \\
\mathrm{n}=86\end{array}$ & Odds ratio & $\begin{array}{l}95 \% \text { Confidence } \\
\text { intervals }\end{array}$ & P-value \\
\hline \multicolumn{6}{|c|}{ Duration of GI symptoms, years, n (\%) } \\
\hline$<5$ & $12(14.6)$ & $14(16.3)$ & 1 & & \\
\hline $5-9$ & $15(18.3)$ & $15(17.4)$ & 1.429 & $0.499-4.091$ & 0.774 \\
\hline $10-19$ & $15(18.3)$ & $14(16.3)$ & 1.538 & $0.532-4.449$ & 0.680 \\
\hline$\geq 20$ & $14(17.1)$ & $14(16.3)$ & 3.889 & $1.348-11.216$ & 0.778 \\
\hline Missing & $26(31.7)$ & $29(33.7)$ & - & - & - \\
\hline$P$ for trend & & & & & 0.763 \\
\hline $\mathrm{P}$ for $\log$ value & & & & & $0.036^{\mathrm{a}}$ \\
\hline \multicolumn{6}{|c|}{ Abdominal pain, mm, n (\%) } \\
\hline$<10$ & $23(28.0)$ & $18(20.9)$ & 1 & & \\
\hline $10-39$ & $24(29.3)$ & $23(26.7)$ & 1.225 & $0.528-2.840$ & 0.637 \\
\hline $40-71$ & $18(22.0)$ & $18(20.9)$ & 1.278 & $0.520-3.138$ & 0.593 \\
\hline$\geq 72$ & $16(19.5)$ & $25(29.1)$ & 1.997 & $0.828-4.813$ & 0.124 \\
\hline$P$ for trend & & & & & 0.133 \\
\hline $\mathrm{P}$ for $\log$ value & & & & & 0.156 \\
\hline \multicolumn{6}{|c|}{ Diarrhoea, mm, n (\%) } \\
\hline 0 & $31(37.8)$ & $22(25.6)$ & 1 & & \\
\hline $2-14$ & $9(11.0)$ & $19(22.1)$ & 2.975 & $1.135-7.793$ & $0.027^{\mathrm{a}}$ \\
\hline $15-54$ & $21(25.6)$ & $20(23.3)$ & 1.342 & $0.591-3.049$ & 0.482 \\
\hline$\geq 55$ & $20(24.4)$ & $23(26.7)$ & 1.620 & $0.720-3.646$ & 0.243 \\
\hline$P$ for trend & & & & & 0.407 \\
\hline $\mathrm{P}$ for $\log$ value & & & & & 0.285 \\
\hline \multicolumn{6}{|c|}{ Constipation, mm, n (\%) } \\
\hline 0 & $30(36.6)$ & 16 (18.6) & 1 & & \\
\hline $2-27$ & $12(14.6)$ & $25(29.1)$ & 3.906 & $1.561-9.778$ & $0.004^{\mathrm{b}}$ \\
\hline $28-69.4$ & $20(24.4)$ & $21(24.4)$ & 1.969 & $0.831-4.662$ & 0.124 \\
\hline$\geq 69.5$ & $19(23.2)$ & $21(24.4)$ & 2.072 & $0.870-4.936$ & 1.000 \\
\hline P for trend & & & & & 0.216 \\
\hline $\mathrm{P}$ for $\log$ value & & & & & 1.00 \\
\hline \multicolumn{6}{|c|}{ Bloating and flatulence, $\mathrm{mm}, \mathrm{n}(\%)$} \\
\hline$<17.5$ & $22(26.8)$ & $20(23.3)$ & 1 & & \\
\hline $17.5-54$ & $19(23.2)$ & $23(26.7)$ & 1.332 & $0.565-3.140$ & 0.513 \\
\hline $55-79$ & $14(17.1)$ & $23(26.7)$ & 1.807 & $0.736-4.440$ & 0.197 \\
\hline$\geq 80$ & $26(31.7)$ & $18(20.9)$ & 0.762 & $0.324-1.787$ & 0.531 \\
\hline $\mathrm{P}$ for trend & & & & & 0.656 \\
\hline $\mathrm{P}$ for $\log$ value & & & & & 0.905 \\
\hline \multicolumn{6}{|c|}{ Vomiting and nausea, $\mathrm{mm}, \mathrm{n}(\%)$} \\
\hline 0 & $39(47.6)$ & $22(25.6)$ & 1 & & \\
\hline $2-8$ & $5(6.1)$ & $19(22.1)$ & 6.736 & $2.209-20.546$ & $0.001^{\mathrm{b}}$ \\
\hline $9-44$ & $19(23.2)$ & $21(24.4)$ & 1.959 & $0.870-4.410$ & 0.104 \\
\hline$\geq 45$ & $18(22.0)$ & $22(25.6)$ & 2.167 & $0.961-4.886$ & 0.062 \\
\hline P for trend & & & & & 0.095 \\
\hline $\mathrm{P}$ for $\log$ value & & & & & $0.040^{\mathrm{a}}$ \\
\hline \multicolumn{6}{|c|}{ Psychological well-being, mm, n (\%) } \\
\hline$<8$ & $22(26.8)$ & $19(22.1)$ & 1 & & \\
\hline $8-29$ & $22(26.8)$ & $21(24.4)$ & 1.105 & $0.469-2.604$ & 0.819 \\
\hline $30-63.4$ & $18(22.0)$ & $23(26.7)$ & 1.480 & $0.620-3.532$ & 0.378 \\
\hline$\geq 63.5$ & $19(23.2)$ & $21(24.4)$ & 1.280 & $0.535-3.063$ & 0.580 \\
\hline$P$ for trend & & & & & 0.460 \\
\hline$P$ for $\log$ value & & & & & 0.434 \\
\hline
\end{tabular}


Table V. Continued.

\begin{tabular}{|c|c|c|c|c|c|}
\hline Characteristics & $\begin{array}{c}\text { AXIN1 } \\
<300 \mathrm{pg} / \mathrm{ml}, \\
\mathrm{n}=82\end{array}$ & $\begin{array}{c}\text { AXIN1 } \\
\geq 300 \mathrm{pg} / \mathrm{ml}, \\
\mathrm{n}=86\end{array}$ & Odds ratio & $\begin{array}{l}95 \% \text { Confidence } \\
\text { intervals }\end{array}$ & P-value \\
\hline \multicolumn{6}{|c|}{ Intestinal symptoms' effect (mm) } \\
\hline$<8.5$ & $27(32.9)$ & $15(17.4)$ & 1 & & \\
\hline $8.5-39$ & $20(24.4)$ & $21(24.4)$ & 1.890 & $0.784-4.554$ & 0.156 \\
\hline $40-74$ & $22(26.8)$ & $20(23.3)$ & 1.636 & $0.682-3.924$ & 0.270 \\
\hline$\geq 75$ & $12(14.6)$ & $28(32.6)$ & 4.200 & $1.665-10.592$ & $0.002^{\mathrm{b}}$ \\
\hline$P$ for trend & & & & & $0.005^{\mathrm{b}}$ \\
\hline$P$ for $\log$ value & & & & & $0.007^{\mathrm{b}}$ \\
\hline \multicolumn{6}{|c|}{ Incomplete evacuation } \\
\hline No symptom & $36(43.9)$ & $31(36.0)$ & 1 & & \\
\hline Symptom & $44(53.7)$ & $49(57.0)$ & 1.293 & $0.689-2.427$ & 0.888 \\
\hline \multicolumn{6}{|c|}{ Defecation urgency } \\
\hline No urgency & $49(59.8)$ & $48(55.8)$ & 1 & & \\
\hline Urgency & $31(37.8)$ & $29(33.7)$ & 0.955 & $0.502-1.818$ & 0.423 \\
\hline
\end{tabular}

association between hs-CRP levels with higher BMI levels may reflect low-grade inflammation due to obesity (37).

F-calprotectin has been reported as a marker for the differentiation between IBS and inflammatory bowel diseases $(16,17)$, and as a potential biomarker for the severity of IBS (12). Measurable F-calprotectin levels were most often noted in participants who experienced incomplete evacuation when defecating, and in participants with a higher degree of constipation. These conditions are characterized by increased straining, which may lead to invasion of leukocytes in the mucosa and measurable calprotectin levels in faeces (38). Therefore, F-calprotectin may reflect straining, rather than an association with endometriosis, since bowel involvement of endometriosis did not affect F-calprotectin levels. However, F-calprotectin levels in the grey zone, and even high levels, may be found in some healthy subjects as well. This effect could possibly be explained by drug intake $(39,40)$. The low number of patients with measurable F-calprotectin levels in the present study suggest that it is not of major importance in endometriosis.

Overall, no correlations between the localisation of endometriosis and the levels of inflammatory biomarkers were found. Therefore, the ability to classify the stage and localisation of endometriosis is a continuous concern for research and is considered important in creating a common classification when comparing case reports and clinical studies.

Several other biomarkers, such as CA-125 and CA-19-9, have also been analysed in patients with endometriosis (6). However, no biomarkers were considered to be useful for the diagnosis of endometriosis $(6,41)$. The usefulness of AXIN1 as a biomarker has to be further examined, independently of other biomarkers. Furthermore, even if AXIN1 is not a useful biomarker, it may be an interesting factor to study to learn more regarding the pathophysiology underlying disease initiation and/or development and clinical manifestations of the disease. Thus, the aim of the present study was to not only to identify biomarkers, but to also understand the mechanisms underlying endometriosis.

The primary strength of the present study was the large sample size of the patients with measurable AXIN1 levels. The primary limitations are the cross-sectional design without the prospective follow-up and the inability to describe the causality of the findings.

In conclusion, in patients with endometriosis, P-AXIN1 levels were negatively correlated with F-calprotectin and humoral inflammatory biomarkers, with the exception of hs-CRP. In addition, they were positively correlated with the duration of endometriosis and the GI symptoms, as well as with vomiting and nausea and the symptoms' effect on quality of life. Increased AXIN1 levels were associated with duration of GI symptoms and the degree of specific GI symptoms. AXIN1 levels were increased in patients with hormonal treatment. The measurement of hs-CRP, F-calprotectin and other humoral biomarkers was determined to be of no value in endometriosis. Future studies are required to determine the effect of hormonal treatment on P-AXIN1, as well as the potential role of AXIN1 in the development of endometriosis and associated symptoms, and its role as a potential biomarker for the disease.

\section{Acknowledgements}

We would like to thank Dr Per Ekström, Professor Lil Valentin and Dr Johanna Nordengren from the Department of Gynecology, Skane University Hospital, Malmö, for identifying and helping with the recruitments of patients.

\section{Funding}

The present study was funded by grants from Bengt Ihre Foundation (2017), Dir Albert Påhlsson's Foundation (2016) and Development Foundation of Region Skane (2018). 


\section{Availability of data and materials}

The datasets used and/or analysed during the present study are available from the corresponding author on reasonable request.

\section{Authors' contributions}

The present study was designed by KD, ME, BR and BO. $\mathrm{KD}, \mathrm{ME}, \mathrm{BR}$ and $\mathrm{BO}$ performed the experiments. $\mathrm{KD}, \mathrm{ME}$ and $\mathrm{BO}$ analysed the data. KD wrote the original draft of the manuscript. ME, BR and BO reviewed and revised the manuscript. All authors read and approved the final manuscript.

\section{Ethics approval and consent to participate}

The present study was performed in accordance with the Declaration of Helsinki. Ethical approval was obtained from the Ethics Review Board of Lund University [approval nos. 2012/564 (09/10/2012) and 2016/56 (03/05/2016)]. All participants provided written informed consent prior to participation.

\section{Patient consent for publication}

All participants provided written informed consent for publication of their data.

\section{Competing interests}

The authors declare that they have no competing interests.

\section{References}

1. Eskenazi B and Warner ML: Epidemiology of endometriosis. Obstet Gynecol Clin North Am 24: 235-258, 1997.

2. Creed J, Maggrah A, Reguly B and Harbottle A: Mitochondrial DNA deletions accurately detect endometriosis in symptomatic females of child-bearing age. Biomark Med 13: 291-306, 2019.

3. Bulun SE, Yilmaz BD, Sison C, Miyazaki K, Bernardi L, Liu S, Kohlmeier A, Yin P, Milad M and Wei J: Endometriosis. Endocr Soc 40: 1048-1079, 2019.

4. Viganò $D$, Zara $F$ and Usai P: Irritable bowel syndrome and endometriosis: New insights for old diseases. Dig Liver Dis 50: 213-219, 2018.

5. Giudice LC and Kao LC: Endometriosis. Lancet 364: 1789-1799, 2004.

6. Fassbender A, Burney RO, O DF, D'Hooghe T and Giudice L: Update on biomarkers for the detection of endometriosis. Biomed Res Int 2015: 130854, 2015.

7. Ek M, Roth B, Engström G and Ohlsson B: AXIN1 in plasma or serum is a potential new biomarker for endometriosis. Int $\mathrm{J} \mathrm{Mol}$ Sci 20: 189, 2019.

8. Kikuchi A: Roles of axin in the Wnt signalling pathway. Cell Signal 11: 777-788, 1999.

9. MacDonald BT, Tamai K and He X: Wnt/beta-catenin signaling: Components, mechanisms, and diseases. Dev Cell 17: 9-26, 2009

10. Shi J, Chi S, Xue J, Yang J, Li F and Liu X: Emerging role and therapeutic implication of Wnt signaling pathways in autoimmune diseases. J Immunol Res 2016: 9392132, 2016.

11. Hod K, Dickman R, Sperber A, Melamed S, Dekel R, Ron Y, Halpern Z, Berliner S and Maharshak N: Assessment of high-sensitivity CRP as a marker of micro-inflammation in irritable bowel syndrome. Neurogastroenterol Motil 23: 1105-1110, 2011.

12. Pletikosic S, Plavsic I, Hauser G and Tkalcic M: Fecal calprotectin and serum chromogranin A as potential biomarkers of irritable bowel syndrome symptom severity. Med Hypotheses 85: 339-342, 2015.
13. Thubert T, Santulli P, Marcellin L, Menard S, M'Baye M, Streuli I, Borghese B, de Ziegler D and Chapron C: Measurement of hs-CRP is irrelevant to diagnose and stage endometriosis: Prospective study of 834 patients. Am J Obstet Gynecol 210: 533. e1-533.e10, 2014.

14. Ni Bhriain H, Trovik J, Wik E, Stefansson IM, Akslen LA, Salvesen HB and Staff AC: Plasma calprotectin concentrations in women with endometrial carcinoma. Gynecol Oncol 114: 491-495, 2009.

15. Kostakis ID, Cholidou KG, Kallianidis K, Perrea D and Antsaklis A: The role of calprotectin in obstetrics and gynecology. Eur J Obstet Gynecol Reprod Biol 151: 3-9, 2010.

16. Yang Z, Clark N and Park KT: Effectiveness and cost-effectiveness of measuring fecal calprotectin in diagnosis of inflammatory bowel disease in adults and children. Clin Gastroenterol Hepatol 12: 253-262. e2, 2014.

17. Mumolo MG, Bertani L, Ceccarelli L, Laino G, Di Fluri G, Albano E, Tapete G and Costa F: From bench to bedside: Fecal calprotectin in inflammatory bowel diseases clinical setting. World J Gastroenterol 24: 3681-3694, 2018.

18. World Medical Association: World medical association declaration of Helsinki: Ethical principles for medical research involving human subjects. JAMA 310: 2191-2194, 2013.

19. Ek M, Roth B, Nilsson PM and Ohlsson B: Characteristics of endometriosis: A case-cohort study showing elevated IgG titers against the TSH receptor (TRAb) and mental comorbidity. Eur J Obstet Gynecol Reprod Biol 231: 8-14, 2018.

20. Bengtsson M, Ohlsson B and Ulander K: Development and psychometric testing of the visual analogue scale for irritable bowel syndrome (VAS-IBS). BMC Gastroenterol 7: 16, 2007.

21. Labmedicin Skåne Analysportalen. Available online: http:// www.analysportalen-labmedicin.skane.se/.

22. Bengtsson M, Hammar O, Mandl T and Ohlsson B: Evaluation of gastrointestinal symptoms In different patient groups using the visual analogue scale for irritable bowel syndrome (VAS-IBS). BMC Gastroenterol 11: 122, 2011.

23. World Health Organization. Global databae on body mass index. Available from: http://www.euro.who.int/en/healthtopics/disease-prevention/nutrition/a-healthy-lifestyle/ body-mass-index-bmi.

24. Moparthi L and Koch S: Wnt signaling in intestinal inflammation. Differentiation 108: 24-32, 2019.

25. Clevers $\mathrm{H}$ and Nusse R: Wnt/ $\beta$-catenin signaling and disease. Cell 149: 1192-1205, 2012.

26. Li VS, Ng SS, Boersema PJ, Low TY, Karthaus WR, Gerlach JP, Mohammed S, Heck AJ, Maurice MM, Mahmoudi T and Clevers H: Wnt signaling through inhibition of $\beta$-catenin degradation in an intact Axin1 complex. Cell 149: 1245-1256, 2012.

27. Arend RC, Londoño-Joshi AI, Straughn JM Jr and Buchsbaum DJ: The Wnt $/ \beta$-catenin pathway in ovarian cancer: A review. Gynecol Oncol 131: 772-779, 2013.

28. Silva-García O, Valdez-Alarcón JJ and Baizabal-Aguirre VM: The Wnt/ $\beta$-catenin signaling pathway controls the inflammatory response in infections caused by pathogenic bacteria. Mediators Inflamm 2014: 310183, 2014.

29. Katoh M: Multi-layered prevention and treatment of chronic inflammation, organ fibrosis and cancer associated with canonical WNT/ $\beta$-catenin signaling activation (Review). Int J Mol Med 42: 713-725, 2018.

30. Ikeda S, Kishida S, Yamamoto H, Murai H, Koyama S and Kikuchi A: Axin, a negative regulator of the Wnt signaling pathway, forms a complex with GSK-3beta and beta-catenin and promotes GSK-3beta-dependent phosphorylation of beta-catenin. EMBOJ 17: 1371-1384, 1998.

31. Song X, Wang S and Li L: New insights into the regulation of Axin function in canonical Wnt signaling pathway. Protein Cell 5: 186-193, 2014.

32. Mukherjee A, Dhar N, Stathos M, Schaffer DV and Kane RS: Understanding how Wnt influences destruction complex activity and $\beta$-catenin dynamics. iScience 6: 13-21, 2018.

33. Matsuzaki S, Botchorishvili R, Pouly JL and Canis M: Targeting the Wnt/beta-pathway in endometriosis: A potentially effective approach for treatment and prevention. Mol Cell Ther 2: 36, 2014.

34. Zhang L, Xiong W, Xiong Y, Liu H and Liu Y: $17 \beta$-Estradiol promotes vascular endothelial growth factor expression via the Wnt $/ \beta$-catenin pathway during the pathogenesis of endometriosis. Mol Hum Reprod 22: 526-535, 2016.

35. Issa B, Onon TS, Agrawal A, Shekhar C, Morrs J, Hamdy S and Whorwell PJ: Visceral hypersensitivity in endometriosis: A new target for treatment? Gut 61: 3667-3672, 2012. 
36. Nilholm C, Roth B and Ohlson B: A dietary intervention with reduction of starch and sucrose leads to reduced gastrointestinal and extra-intestinal symptoms in IBS patients. Nutrients 11: pii: E1662, 2019.

37. Daryabor G, Kabelitz D and Kalantar K: An update on immune dysregulation in obesity-related insulin resistance. Scand J Immunol 89: e12747, 2019.

38. Røseth AG, Schmidt PN and Fagerhol MK: Correlation between faecal excretion of indium-111-labelled granulocytes and calprotectin, a granulocyte marker protein, in patients with inflammatory bowel disease. Scand J Gastroenterol 34: 50-54, 1999.

39. Andréasson K, Scheja A, Saxne T, Ohlsson B and Hesselstrand R: Faecal calprotectin: A biomarker of gastrointestinal disease in systemic sclerosis. J Intern Med 270: 50-57, 2011.
40. Ek M, Roth B, Valentin L, Nordengren J and Ohlsson B: Autoantibodies common in patients with gastrointestinal diseases are not found in patients with endometriosis: A cross-sectional study. Eur J Obstet Gynecol Reprod Biol 240: 370-374, 2019.

41. Hirsch M, Begum MR, Paniz É, Barker C and Davis CJ: Diagnosis and management of endometriosis: A systematic review of international and national guidelines. BJOG 125: 556-564, 2018.

This work is licensed under a Creative Commons Attribution-NonCommercial-NoDerivatives 4.0 International (CC BY-NC-ND 4.0) License. 